\title{
TI.44.1
}

\section{2nd Annual PKI Research Workshop Pre-Proceedings}

- PDF: pki03pp.pdf

\section{More Information}

\begin{tabular}{|l|l|}
\hline Repository ID & TI.44.1 \\
\hline Persistent URL & http://doi.org/10.26869/TI.44.1 \\
\hline Title & 2nd Annual PKI Research Workshop Pre-Proceedings \\
\hline Authors & Ken Klingenstein, Carl Ellison, et al \\
\hline Sponsor & NIH, NIST, Internet2 \\
\hline Review & \\
\hline Status & Legacy \\
\hline Publish Date & April 28-29, 2003 \\
\hline DOI & 10.26869/TI.44.1 \\
\hline Signature & \\
\hline Deprecated & No \\
\hline Future Review & \\
\hline Supersedes & \\
\hline Format & PDF \\
\hline Related Docs & \\
\hline Development Location & \\
\hline IP Framework & \\
\hline Subject Tags & \\
\hline Notes & \\
\hline
\end{tabular}

